\title{
Intimate partner violence and psychosocial health, a cross-sectional study in a pregnant population
}

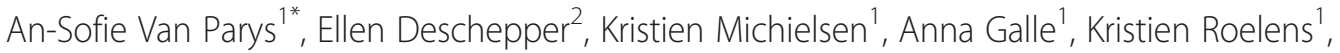
Marleen Temmerman ${ }^{1}$ and Hans Verstraelen ${ }^{3}$

\begin{abstract}
Background: The objective of this paper is to explore whether IPV 12 months before and/or during pregnancy is associated with poor psychosocial health.

Methods: From June 2010 to October 2012, a cross-sectional study was conducted in 11 antenatal care clinics in Belgium. Consenting pregnant women were asked to complete a questionnaire on socio-demographics, psychosocial health and violence in a separate room. Overall, 2586 women were invited to participate and we were able to use data from 1894 women (73.2 \%) for analysis. Ethical clearance was obtained in all participating hospitals.

Results: We found a significant correlation between IPV and poor psychosocial health: within the group of women who reported IPV, $53.2 \%(n=118)$ had poor psychosocial health, as compared to $21 \%(n=286)$ in the group of women who did not report IPV $(P<0.001)$.

Lower psychosocial health scores were associated with increased odds of reporting IPV (aOR 1.55; 95 \% Cl 1.39-1.72), with adjustments made for the language in which the questionnaire was filled out, civil/marital status, education and age. In other words, a decrease of 10 points on the psychosocial health scale (total of 140) increased the odds of reporting IPV by $55 \%$.

When accounting for the 6 psychosocial health subscales, the analysis revealed that all subscales (depression, anxiety, self-esteem, mastery, worry and stress) are strongly correlated to reporting IPV. However, when accounting for all subscales simultaneously in a logistic regression model, only depression (aOR 0.87; $95 \% \mathrm{Cl} 0.84-0.91$ ) and stress (aOR 0.85; $95 \%$ Cl 0.77-095) remained significantly associated with IPV. The association between overall psychosocial health and IPV remained significant after adjusting for socio-demographic status.

Conclusion: Our research corroborated that IPV and psychosocial health are strongly associated. Due to the limitations of our study design, we believe that future research is needed to deepen understanding of the multitude of factors involved in the complex interactions between IPV and psychosocial health.
\end{abstract}

Keywords: Intimate partner violence, Abuse, Pregnancy, Psychosocial health

\footnotetext{
*Correspondence: ansofie.vanparys@ugent.be

'Department of Obstetrics and Gynaecology, Faculty of Medicine and Health Sciences, International Centre for Reproductive Health, Ghent University, De Pintelaan 185, UZP 114, 9000 Ghent, Belgium

Full list of author information is available at the end of the article
}

C 2016 Van Parys et al. Open Access This article is distributed under the terms of the Creative Commons Attribution 4.0 International License (http://creativecommons.org/licenses/by/4.0/, which permits unrestricted use, distribution, and reproduction in any medium, provided you give appropriate credit to the original author(s) and the source, provide a link to the Creative Commons license, and indicate if changes were made. The Creative Commons Public Domain Dedication waiver (http://creativecommons.org/publicdomain/zero/1.0/) applies to the data made available in this article, unless otherwise stated. 


\section{Background}

Intimate partner violence (IPV) is currently recognised as a global health problem with serious clinical and societal implications, which affects women and men from all backgrounds, regardless of age, ethnicity, socio-economic status, sexual orientation or religion [1-4]. IPV is defined as any behaviour within a present or former intimate relationship that leads to physical, sexual or psychological harm, including acts of physical aggression, sexual coercion, psychological abuse and controlling behaviour patterns [5]. IPV is also known as domestic/family violence, spouse/partner abuse/assault, battering, violence against women or gender-based violence [6-8]. Based on the Centers for Disease Control and Prevention's definition of IPV [9], we have chosen to consistently use the term 'violence' for physical and sexual types of violence, and 'abuse' for psychological types. The word 'abuse' clearly refers to a broader range of behaviours than the word 'violence,' which is often associated with severe forms of violent behaviour.

Pregnancy and childbirth mark an important turning point at which the roles and relationships of couples and their families are redefined on different levels. While parenthood can bring joy, it also confronts couple relationships with new challenges $[10,11]$. As pregnancy may generate changes in physical, emotional, social and economic needs, it can be a stressful time. This period is associated with increased demands on individual capacities, the intimate partner relationship and household economic resources, and a reduction in leisure time and opportunities to socialise, which can exert adverse effects on emotional wellbeing [10]. Individual and dyadic coping strategies tend to decrease under stress, leading to an increased risk of physical and psychological aggression [12-14]. The vulnerable period for IPV associated with pregnancy extends further than the time between conception and birth - from a year before conception until one year after childbirth [4, 12-15].

A wide range of prevalence rates, from 3 to $30 \%$, have been reported for IPV around the time of pregnancy. Prevalence rates are mainly situated at the high end of the continuum in African and Latin American countries, and at the lower end in European and Asian countries. Although estimates are highly variable due to methodological challenges, the majority of studies show rates within the range of 3.9 to $8.7 \%[3,4,6,8,10-17]$. Although the exact prevalence of IPV around the time of pregnancy remains unclear, it is evident that it affects a substantial group of women. In Belgium, we recently showed [17] that as many as $15.8 \%$ (95 \% CI 14.2-17.7) of women experience IPV (incl. psychological abuse) before and/or during pregnancy. In other words IPV during the perinatal period is more common than several maternal physical health conditions (e.g. pre- eclampsia, placenta praevia), yet IPV receives considerably less attention within perinatal care [3, 4, 18, 19]. The Belgian perinatal health care system is based on the bio-medical model [20] with obstetrician/gynaecologists (ob/gyn's) not only accounting for obstetric and gynaecologic pathology, but also acting as primary care physicians to the general female population, e.g. in providing primary obstetric care and in offering preventive women's health medicine [16, 21]. Although pregnancy brings women into regular contact with the health care system and therefore offers strategic opportunities to identify and ameliorate psychosocial concerns and risk factors [22], screening or systematic inquiry for IPV and/ or psychosocial health is not part of routine perinatal care (yet).

In recent decades, research from the Western world, and increasingly, from low and middle income countries [23], has generated growing evidence that violence is associated with detrimental effects on the physical health of women, men and children, such as infection, miscarriage/abortion, placental abruption, foetal injury and perinatal death $[8,18,19,24-35]$. Evidence is emerging that on the one hand, poor psychosocial health is a negative consequence of IPV, and on the other hand, poor psychosocial health is simultaneously found to be a risk factor for IPV. Moreover, poor psychosocial health status is linked to adverse pregnancy outcomes. Women reporting depressive symptoms and poor overall psychosocial health during pregnancy are at increased risk of low birth weight (LBW) and preterm birth [36]. Furthermore, reporting IPV, is associated with increased risk for anxiety disorders, eating disorders, anxiety attacks, nervousness, concentration problems, sexual dysfunctions, fear of intimacy, loss of self-esteem, psychosomatic complaints (e.g. headaches), pre- and postnatal depression, trauma symptoms (such as sleeping problems, flashbacks, panic attacks) posttraumatic stress syndrome, postpartum psychosis, and (attempted) suicide [18, 19, 24-35]. Additionally, IPV is strongly linked with harmful health behaviours such as using tobacco, alcohol or illicit drugs, poor maternal nutrition, and high-risk sexual behaviour $[2,8,18,19$, 24-28, 31-35, 37-41].

The objective of this paper is to explore whether IPV 12 months before and/or during pregnancy is associated with poor psychosocial health in Flanders, Belgium.

\section{Methods}

\section{Setting/study population}

We conducted a multi-centre cross-sectional study in Flanders, the Northern part of Belgium. The Belgian perinatal health care system is based on the medical model [20] and is generally considered to be highly accessible, with women choosing their own health care provider(s). 
Obstetricians/gynaecologists (OB/GYN) merely function as primary perinatal health care providers and the majority of the care is hospital-based. Screening or systematic inquiry for IPV is not part of routine perinatal care.

This study was part of an RCT (Randomized Controlled Trial) that aimed to assess the impact of an intervention on psychosocial health, IPV, safety- and helpseeking behaviour. The methods have been previously published [20] and will only be summarized here.

Participants were recruited between June 2010 and October 2012 in 11 antenatal care clinics that were selected through a convenience sample (based on geographic location, including rural and urban settings, small and large hospitals). The selection criteria for participants were: being pregnant, minimum 18 years old and able to fill out a Dutch, French or English questionnaire. Overall, 2586 women were invited to participate and we were able to use data from 1894 women $(73.2 \%)$ for analysis. The study was introduced by the midwife or receptionist as a survey on difficult moments and feelings during pregnancy. Informed consent was obtained from all participants and consenting women were invited to fill out the questionnaire in a separate room without any accompanying person present. The questionnaire was returned to the health professional in a coded and sealed envelope. If the woman was unable to fill in the questionnaire in private, she was excluded from the study for safety reasons. All measures were taken to ensure that women could get additional support (from social services) if this was deemed necessary by the respondent or the staff. The information letter clearly indicated that the aim of the study was not to provide support or guidance. If women needed additional support (after filling out the questionnaire), they were referred to a $24 / 24$ h telephone hotline. The involvement and training provided to the recruiting professionals was kept to a strict minimum since the aim of the RCT, of which this study was part, is to measure the effect of intervention in as unbiased a way as possible. The study was approved by the Ethics Committee of Ghent University and local ethical clearance was obtained from all 11 participating hospitals (Ethisch Comité Middelheim Ziekenhuis Netwerk Antwerpen, Ethisch Comité Universitair Ziekenhuis Antwerpen, Ethisch Comité Onze Lieve Vrouw Ziekenhuis Aalst, Ethisch Comité Gasthuis Zusters Ziekenhuis St Augustinus Antwerpen, Ethisch Comité Algemeen Ziekenhuis Sint Jan Brugge, Ethisch Comité Algemeen Ziekenhuis Jan Palfijn Gent, Ethisch Comité Onze Lieve Vrouw van Lourdes Ziekenhuis Waregem, Ethisch Comité Universitair Ziekenhuis Gent, Ethisch Comité Algemeen Ziekenhuis Groeninge Kortrijk, Ethisch Comité Virga Jesse Ziekenhuis Hasselt, Ethisch Comité Ziekenhuis Oost-Limburg Genk) (Belgian registration number 67020108164). The trial was registered at www.cli nicaltrials.gov, identifier (NCT01158690).

The overall response rate was $76.7 \%$.

Figure 1 provides a flow diagram of the recruitment.

\section{Questionnaire/measures}

The questionnaire consisted of four main parts: sociodemographics, psychosocial health, violence and satisfaction with care. This paper focuses on the correlation of IPV with psychosocial health, while results on IPV prevalence and the evolution of IPV 12 months before and during pregnancy were published in another paper [17].

Physical and sexual (partner) violence was measured through an adapted version of the Abuse Assessment Screen (AAS) [42], which was adapted in consultation with one of the authors (Prof. dr. Judith McFarlane). To measure psychological abuse, we used an adapted version of the WHO-questionnaire [6]. Based on the limited available literature $[1,6,43-50]$ and after long debate and extensive consultations with several experts in the field, we constructed a 7-item scale of questions with answer options ranging from 0 to 4 and we decided to use a cutoff value of $4 / 28$ as a threshold for psychological abuse. We previously documented the assessment of abuse in detail [17]. Our scale had good internal consistency, with

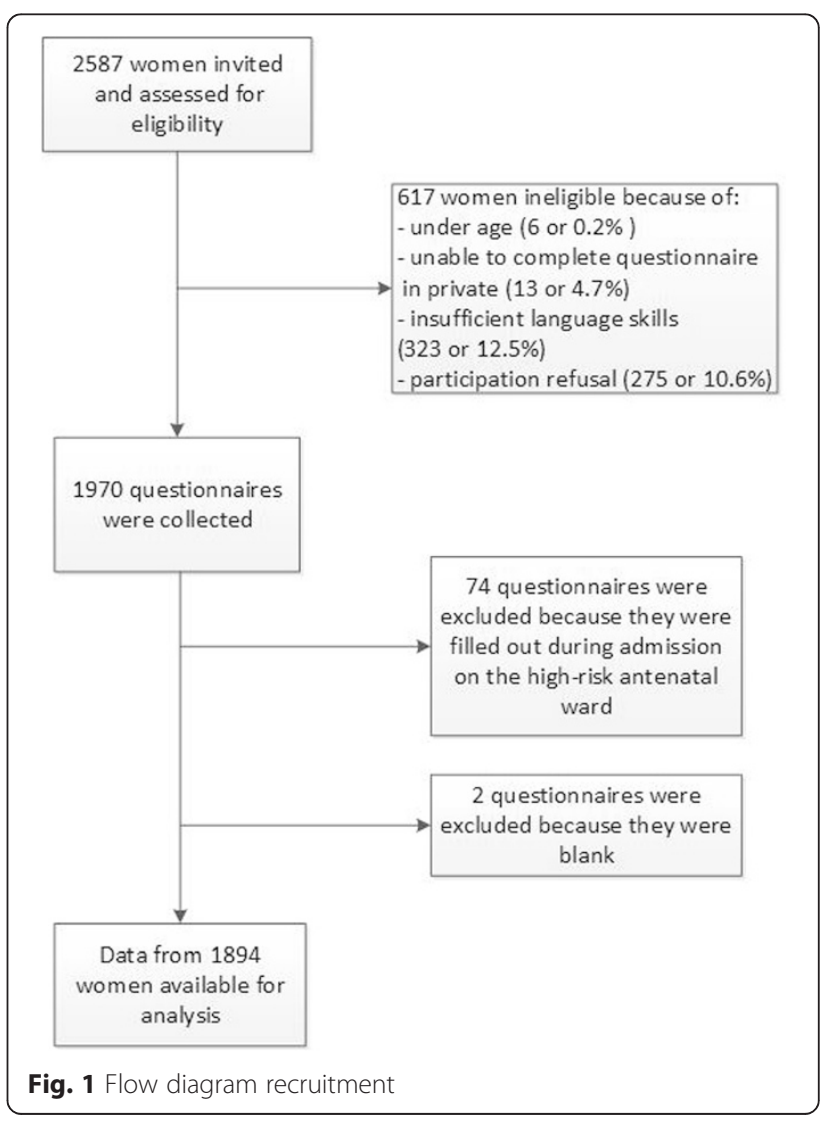


a Cronbach's $\alpha$ value of 0.85 for 12 months before pregnancy and of 0.83 during pregnancy. For the purpose of this paper, we used a dichotomised variable including physical and/or sexual and/or psychological partner violence 12 months before pregnancy and/or during pregnancy.

Psychosocial health was measured through the Abbreviated Psychosocial Scale [51]. This scale is composed of 5 existing scales, namely, for trait anxiety (Speilberger Trait Anxiety Scale), self-esteem (Rosenberg Self-Esteem Scale), mastery (Pearlin Mastery Scale), depression (Centre for Epidemiologic Studies Depression Scale) and subjective stress (Schar Subjective Stress Scale). The Abbreviated Psychosocial Scale is well-validated and was recently identified as the best currently available instrument for measuring multiple psychopathological symptoms [52]. It consists of 6 subscales: negative affect (depression), positive affect (anxiety), positive selfesteem, low mastery, worry (anxiety) and stress. The scale consists of 28 questions, with response alternatives scored from 1 to 5 , resulting in a minimum score of 28 , indicating poor psychosocial health, and a maximum score of 140, indicating good psychosocial health. If one answer is missing, the overall score is coded as missing a value. Unfortunately, no clear clinical cut-off values for psychosocial health are currently available. Therefore, most authors [36, 51-55] use the median or P25-value as a threshold to dichotomize the scale into 'poor' or 'good' psychosocial health. Due to the lack of a clinical cut-off value, we used the scale as a continuous variable where possible. The scale has a Cronbach's $\alpha$ of 0.93 , indicating a high degree of reliability and internal consistency.

\section{Data analysis}

A descriptive analysis of socio-demographic variables, IPV and psychosocial health was performed. The bivariate correlation between IPV and psychosocial health was explored using the Pearson $\mathrm{chi}^{2}$ test. Binary logistic regression analysis was used to investigate the unadjusted and adjusted odds ratios (95\% confidence intervals) of reporting IPV correlated to psychosocial health (total score and subscale scores). Model selection was based on best model fit, statistical significance levels and clinical relevance. P- values below 0.05 were considered to be statistically significant. All statistical analyses were performed with IBM SPSS statistics software (version 22).

This research adhered to the STROBE guidelines for cross-sectional studies as outlined in http://www.strobestatement.org/fileadmin/Strobe/uploads/checklists/STR OBE_checklist_v4_cross-sectional.pdf (checklist added as Additional file 1).

\section{Results}

\section{Socio-demographic data}

The mean age of the women in our sample $(n=1894)$ was 28.9 years (SD 4.5) and the median gestational age was 23.9 weeks (IQR: 19-30). The large majority (95\%) of the women were married or living together with their partners; $5 \%$ were divorced, separated or single. Sixtytwo percent had completed higher education and $37.8 \%$ had not. Most women $(97.5 \%)$ chose to fill out the questionnaire in Dutch, $0.9 \%$ in French and $1.6 \%$ in English. More details are presented in Table 1.

\section{IPV prevalence}

The overall percentage of IPV 12 months before and/ or during pregnancy was $15.8 \%$ (95 \% CI 14.2-17.7) $(n=270)$, while it was $14.3 \%$ (95\% CI 12.7-16.0) $(n=$ 246) 12 months before pregnancy, and $10.6 \%$ (95\% CI 9.2-12.1) during pregnancy, as we have previously reported in detail [17]. Physical partner violence before as well as during pregnancy was reported by $2.5 \%$ (95\% CI 1.8-3.3) of the respondents, sexual violence

Table 1 Socio-demographic characteristics of sample $(n=1894)$

\begin{tabular}{|c|c|c|}
\hline Characteristics & Frequency (n) & Percent \\
\hline \multicolumn{3}{|l|}{ Age $(n=1842)$ - years } \\
\hline $15-19$ & 31 & 1.7 \\
\hline $20-24$ & 262 & 14.2 \\
\hline $25-29$ & 742 & 40.3 \\
\hline $30-34$ & 626 & 34.0 \\
\hline $35-39$ & 149 & 8.1 \\
\hline $40-44$ & 31 & 1.7 \\
\hline $45-49$ & 1 & 0.1 \\
\hline \multicolumn{3}{|l|}{ Civil/marital status $(n=1880)$} \\
\hline Married & 928 & 49.4 \\
\hline Living together & 857 & 45.6 \\
\hline Divorced or separated & 13 & 0.7 \\
\hline Single & 82 & 4.4 \\
\hline \multicolumn{3}{|l|}{ Education $(n=1878)$} \\
\hline None & 34 & 1.8 \\
\hline Primary education & 76 & 4.0 \\
\hline Secondary education & 601 & 32.0 \\
\hline Non-university higher education & 800 & 42.6 \\
\hline University higher education & 367 & 19.5 \\
\hline \multicolumn{3}{|l|}{ Language questionnaire $(n=1894)$} \\
\hline Dutch & 1846 & 97.5 \\
\hline French & 17 & 0.9 \\
\hline English & 31 & 1.6 \\
\hline
\end{tabular}


by $0.9 \%$ (95 \% CI 0.5-1.4), and psychological abuse by $14.9 \%$ (95 \% CI 13.3-16.7). The proportion of missing values ranged between $4 \%(n=75)$ for physical and sexual violence and $10.2 \%(n=193)$ for psychological abuse.

\section{Psychosocial health}

The median score for psychosocial health in our sample was 111 (IQR: 100-120), with a range from 55 to 140. The proportion of missing values was $10.1 \%$.

As noted above, the psychosocial health scale consists of 6 subscales: negative affect (depression), positive affect (anxiety), positive self-esteem, low mastery, worry (anxiety) and stress. Table 2 provides an overview of the subscale scores for the total population.

\section{Correlation of IPV and psychosocial health}

The bivariate analysis demonstrated a statistically significant correlation between IPV and psychosocial health. Within the group of women that reported IPV, $53.2 \%$ $(n=118)$ had poor psychosocial health scores, as compared to $21 \%(n=286)$ in the group of women that did not report IPV $(P<0.001)$. Conversely, it can be stated that $29.2 \%(n=118)$ of the women with poor psychosocial health reported IPV, whereas $8.8 \%(n=104)$ of women with good psychosocial health reported IPV $(P<0.001)$.

\section{Correlation between psychosocial health, socio- demographics and IPV}

Using a multivariable model, we found that a lower total psychosocial health score was associated with increased odds of reporting IPV (aOR 1.04; 95\%CI 1.03-1.06), adjusted for the language in which the questionnaire was filled out, civil/marital status, education and age. This correlation means that a decrease of only one point on the total psychosocial health scale of 140 points is associated with an increased adjusted odds of reporting IPV of $4 \%$. In other words, a decrease of 10 points on the scale is associated with an increased adjusted odds of reporting IPV of 55 \% (aOR 1.55; 95 \% CI 1.39-1.72).

When accounting for the 6 psychosocial health subscales, as shown in Table 3, the binary analysis revealed that all psychosocial health subscales (depression, anxiety, self-esteem, mastery, worry and stress) were strongly correlated to reporting IPV. However, when accounting for all subscales simultaneously in a logistic regression model, only depression and stress remained significantly associated with IPV. The association between total psychosocial health and IPV remained significant after adjusting for socio-demographic status. All socio-demographic factors except age were significantly associated with reporting IPV.

\section{Discussion}

In this multi-centre cohort of pregnant women, we found a strong correlation between IPV and psychosocial health. Several other researchers have previously demonstrated a correlation between reporting IPV and poor psychosocial health $[2,8,18,24-28,31-34,38,56-58]$. Notably, poor psychosocial health is frequently reported as a negative consequence of IPV, and simultaneously, psychosocial health is found to be a risk factor for IPV. As this association has been repeatedly documented mostly in crosssectional studies, it remains to be determined whether poor psychosocial health puts women at risk of IPV, or whether IPV induces worse psychosocial health, though it is plausible that both pathways co-exist. Literature on this specific matter is scarce; most studies have focussed on the association between poor psychosocial health and pregnancy outcomes such as low birth weight and prematurity, though the influence of psychosocial factors (such as stress, anxiety, and depression) on birth outcomes remains inconclusive $[36,51,52]$. However, psychosocial resources including self-esteem and mastery have been reported to protect women against stress from life events and chronic strains. These psychosocial resources could be even more relevant when women adapt to manage their lives and cope with the stress and vulnerability associated with IPV during pregnancy [54].

Our data further suggest that, after taking all measured variables into account, the correlation between IPV and psychosocial health was mainly explained by "depression" and "stress" as psychosocial health indices. It has been noted that scales measuring affective states such depression or anxiety are likely to be highly correlated with each other and measure generalized distress rather than symptoms unique to depression or anxiety [51]. Our results confirm the finding that there is a strong correlation between the different psychosocial health subscales. The strong association between the total psychosocial health scale and IPV might indeed refer to a more general form of distress in our population interconnected with a multitude of factors.

Table 2 Overview subscales psychosocial health

\begin{tabular}{|c|c|c|c|c|c|c|}
\hline & Subscale depression & Subscale anxiety & $\begin{array}{l}\text { Subscale } \\
\text { self-esteem }\end{array}$ & Subscale mastery & Subscale worry & Subscale stress \\
\hline Median total sample (IQR) & $28(25-31)$ & $24(23-27)$ & $16(15-18)$ & $24(21-27)$ & $11(9-13)$ & $7(5-8)$ \\
\hline Median score women reporting IPV (IQR) & $25(21-28)$ & $23(20-24)$ & $16(14-17)$ & $22(18-24)$ & $10(8-11)$ & $6(5-7)$ \\
\hline Median scores women not reporting IPV (IQR) & $29(25-31)$ & $25(23-27)$ & $16(15-18)$ & $25(22-27)$ & $11(10-13)$ & $7(6-8)$ \\
\hline Maximum score subscales & 35 & 30 & 20 & 30 & 15 & 10 \\
\hline
\end{tabular}


Table 3 Association of psychosocial health with reporting IPV

\begin{tabular}{|c|c|c|c|c|}
\hline Subscales psychosocial health & Unadjusted OR (95\% Cl) & $P$-value & Adjusted OR (95 \% Cl) & $P$-value \\
\hline Depression & $0.83(0.80-0.86)$ & $<0.001$ & $0.87(0.84-0.91)$ & $<0.001$ \\
\hline Anxiety & $0.82(0.79-0.85)$ & $<0.001$ & / & / \\
\hline Self-esteem & $0.86(0.81-0.90)$ & $<0.001$ & / & / \\
\hline Mastery & $0.84(0.81-0.87)$ & $<0.001$ & / & / \\
\hline Worry & $0.78(0.73-0.83)$ & $<0.001$ & / & / \\
\hline Stress & $0.73(0.67-0.79)$ & $<0.001$ & $0.85(0.77-095)$ & 0.005 \\
\hline Total psychosocial health score & $0.95(0.94-0.96)$ & $<0.001$ & / & / \\
\hline \multicolumn{5}{|l|}{ Socio-demographics } \\
\hline Age & / & / & $1.00(0.97-1.04)$ & 0.700 \\
\hline Civil/marital status (single vs. married/cohabiting) & / & / & $3.53(1.89-6.60)$ & $<0.001$ \\
\hline \multicolumn{5}{|l|}{ Education } \\
\hline No/primary vs. higher & / & / & $5.62(3.01-10.51)$ & $<0.001$ \\
\hline Secondary vs. higher & / & / & $2.48(1.78-3.45)$ & $<0.001$ \\
\hline Language questionnaire (not Dutch vs. Dutch) & / & / & $5.75(2.4-13.7)$ & $<0.001$ \\
\hline
\end{tabular}

Recently, there has been a shift towards envisaging psychosocial health as a multidimensional concept [52]. We acknowledge that psychosocial health is a complex construct with many known and, presumably, many unknown determinants, although our study was not designed to explore this. Future research should be done to try to shed some light on the multitude of factors involved in the complex interaction between psychosocial health and IPV.

Our results need to be viewed within the context of certain limits. There is currently a lack of agreement on standard measures for psychological (partner) abuse/ violence and in an effort to tackle this problem, we decided to construct our own scale and threshold for psychological abuse cut-off value. The threshold we chose for psychological abuse was based on a thorough literature search and extensive discussions with experts in the field. Nevertheless, it remains an arbitrary choice that is open for discussion. We have some indication that the cut-off might be on the low side, but this hypothesis obviously needs further investigation. Furthermore, our study design did not allow us to determine causal pathways between the factors analysed. Moreover, we were not able to analyse in depth the multitude of factors involved in the complex interaction between IPV and psychosocial health, and as a consequence, might have oversimplified reality. The findings presented in this paper are based on a sample of the Belgian obstetrical population and cannot be generalised to other populations or health care systems without the necessary caution.

\section{Conclusion}

Our research has demonstrated that IPV and psychosocial health are strongly associated. Due to the cross-sectional nature of our study design, we are not able to make any statements on causality with regard to these associations. However, it seems reasonable that a multitude of factors could have influenced the interaction, and more longitudinal and in-depth, qualitative analysis needs to be done to shed light on the complex interactions and confounding factors that define the relationship between IPV and psychosocial health.

Furthermore, linked to the important role of psychosocial health found in our study, we believe that the recommendation to routinely screen for IPV during pregnancy should be broadened and that IPV should not been seen as an isolated theme. IPV research is providing increasing evidence that addressing the multitude of risk factors related to IPV simultaneously has a larger effect than addressing a single factor. Therefore, we would like to join the growing number of authors advocating for the inclusion of IPV within a broader psychosocial health assessment as a standard part of antenatal care. Addressing psychosocial health in antenatal care has the potential to improve the health and well-being of women and their families.

\section{Additional file}

Additional file 1: STROBE Statement-Checklist of items that should be included in reports of cross-sectional studies. (PDF $18 \mathrm{~kb}$ )

\section{Abbreviations}

AAS: Abuse Assessment Screen; IPV: Intimate Partner Violence; IQR: Inter Quartile Range; OB/GYN: Obstetrician/Gynaecologist; RCT: Randomized Controlled Trial; SD: Standard Deviation; SES: Socio Economic Status; SPSS: Statistical Package for the Social Sciences..

\section{Competing interests}

The authors declare that they have no competing interests. 


\section{Authors' contributions}

ASVP conceived the study, acquired the data, performed the analysis and drafted the manuscript. ED assisted ASVP with the statistical analysis. KM, AG, MT and HV participated in the design of the study, were involved in drafting the article, and gave critical input. All authors read and approved the final manuscript.

\section{Acknowledgements}

We would like to thank all the women that participated in our study for the bravery they showed filling out a questionnaire on this difficult topic. Our thanks are due to Prof Olivier Degomme for methodological support, and to Prof Fred Louckx, Prof. Kristien Michielsen, Dr. Ines Keygnaert, and Ms. Heleen Vermandere for their support and useful comments.

\section{Author details}

${ }^{1}$ Department of Obstetrics and Gynaecology, Faculty of Medicine and Health Sciences, International Centre for Reproductive Health, Ghent University, De Pintelaan 185, UZP 114, 9000 Ghent, Belgium. ²Department of Public Health, Biostatistics Unit, Faculty of Medicine and Health Sciences, Ghent University, Ghent, Belgium. ${ }^{3}$ Department of Obstetrics and Gynaecology, Faculty of Medicine and Health Sciences, Ghent University, Ghent, Belgium.

\section{Received: 21 January 2015 Accepted: 19 October 2015} Published online: 11 November 2015

\section{References}

1. WHO. Global and regional estimates of violence against women: prevalence and health effects of IPV and non-partner sexual violence. 2014.

2. Daoud N, Urquia ML, O'Campo P, Heaman M, Janssen PA, Smylie J, et al. Prevalence of abuse and violence before, during, and after pregnancy in a national sample of Canadian women. Am J Public Health. 2012;102:1893901. doi:10.2105/AJPH.2012.300843.

3. Devries KM, Kishor S, Johnson H, Stockl H, Bacchus L, Garcia-Moreno C, et al. Intimate partner violence during pregnancy: analysis of prevalence data from 19 countries. Reprod Health Matters. 2010;18:158-70. doi:10.1016/ S0968-8080(10)36533-5.

4. Taillieu TL, Brownridge DA. Violence against pregnant women: Prevalence, patterns, risk factors, theories, and directions for future research. Aggress Violent Behav. 2010;15:14-35.

5. Heise L, Ellsberg M, Gottmoeller M. A global overview of gender-based violence. Int J Gynaecol Obstet. 2002;78 Suppl 1:S5-S14. S0020729202000383 [pii].

6. Garcia-Moreno C, Heise L, Jansen HAFM, Ellsberg M, Watts C. Public health Violence against women. Science. 2005;310:1282-3.

7. Hegarty KL, Gunn JM, O'Doherty LJ, Taft A, Chondros P, Feder G, et al. Women's evaluation of abuse and violence care in general practice: a cluster randomised controlled trial (weave). BMC Public Health. 2010;10:2 doi:10.1186/1471-2458-10-2

8. Krug EG, Mercy JA, Dahlberg LL, Zwi AB. The world report on violence and health. Lancet. 2002;360:1083-8.

9. Saltzman L, Fanslow J, McMahon P, Shelly G. Intimate Partner Violence: Uniform definitions and recommendaded data elements. Version. 1999;1.

10. Fisher J, de Mello MC, Patel V, Rahman A, Tran T, Holton S, et al. Prevalence and determinants of common perinatal mental disorders in women in lowand lower-middle-income countries: a systematic review. Bull World Health Organ. 2012;90:139-49

11. Kan ML, Feinberg ME. Measurement and Correlates of Intimate Partner Violence Among Expectant First-Time Parents. Violence Vict. 2010;25:319-31.

12. Martin SL, Harris-Britt A, Li Y, Moracco KE, Kupper LL, Campbell JC. Changes in intimate partner violence during pregnancy. J Fam Violence. 2004;19:201-10.

13. Jasinski JL. Pregnancy and domestic violence: a review of the literature. Trauma Violence Abuse. 2004:5:47-64 doi:10.1177/1524838003259322.

14. Charles P, Perreira KM. Intimate partner violence during pregnancy and 1-year post-partum. J Fam Violence. 2007;22:609-19.

15. Saltzman LE, Johnson CH, Gilbert BC, Goodwin MM. Physical abuse around the time of pregnancy: an examination of prevalence and risk factors in 16 states. Matern Child Health J. 2003:7:31-43.

16. Roelens $K$, Verstraelen $H$, Van EK, Temmerman M. Disclosure and healthseeking behaviour following intimate partner violence before and during pregnancy in Flanders, Belgium: a survey surveillance study. Eur J Obstet Gynecol Reprod Biol. 2008;137:37-42. doi:10.1016/j.ejogrb.2007.04.013.
17. Van Parys AS, Deschepper E, Michielsen K, Temmerman M, Verstraelen H. Prevalence and evolution of intimate partner violence before and during pregnancy: a cross-sectional study. BMC Pregnancy Childbirth. 2014;14:294. doi:10.1186/1471-2393-14-294.

18. Chambliss LR. Intimate partner violence and its implication for pregnancy. Clin Obstet Gynecol. 2008;51:385-97.

19. Bacchus L, Mezey G, Bewley S. Domestic violence: prevalence in pregnant women and associations with physical and psychological health. Eur J Obstet Gynecol Reprod Biol. 2004;113:6-11.

20. Christiaens W, Verhaeghe M, Bracke P. Childbirth expectations and experiences in Belgian and Dutch models of maternity care. J Reprod Infant Psychol. 2008;26:309-22.

21. Roelens K, Verstraelen H, Van EK, Temmerman M. A knowledge, attitudes, and practice survey among obstetrician-gynaecologists on intimate partner violence in Flanders, Belgium. BMC Public Health. 2006;6:238 doi:10.1186/1471-2458-6-238

22. Blackmore ER, Carroll J, Reid A, Biringer A, Glazier RH, Midmer D, et al. The use of the Antenatal Psychosocial Health Assessment (ALPHA) tool in the detection of psychosocial risk factors for postpartum depression: a randomized controlled trial. J Obstet Gynaecol Can. 2006;28:873-8.

23. Shamu S, Abrahams N, Temmerman M, Musekiwa A, Zarowsky C. A Systematic Review of African Studies on Intimate Partner Violence against Pregnant Women: Prevalence and Risk Factors. Plos One. 2011;6.

24. Cripe SM, Sanchez SE, Sanchez E, Quintanilla BA, Alarcon CH, Gelaye B, et al. Intimate Partner Violence During Pregnancy: A Pilot Intervention Program in Lima, Peru. J Interpers Violence. 2010;25:2054-76.

25. Rose L, Bhandari S, Marcantonio K, Bullock L, Sharps P. Impact of Family and Personal History of Abused Pregnant Women on Their Coping With Current Intimate Partner Violence. Int J Qual Methods. 2010;9:382-3.

26. Johnson JK, Haider F, Ellis K, Hay DM, Lindow SW. The prevalence of domestic violence in pregnant women. BJOG. 2003;110:272-5.

27. Taft AJ, Small R, Hegarty KL, Lumley J, Watson LF, Gold L. MOSAIC (MOthers' Advocates In the Community): protocol and sample description of a cluster randomised trial of mentor mother support to reduce intimate partner violence among pregnant or recent mothers. BMC Public Health. 2009;9.

28. Campbell JC. Abuse during pregnancy: a quintessential threat to maternal and child health - so when do we start to act? Can Med Assoc J. 2001;164:1578-9.

29. Bohn DK, Tebben JG, Campbell JC. Influences of income, education, age, and ethnicity on physical abuse before and during pregnancy. J Obstet Gynecol Neonatal Nurs. 2004;33:561-71.

30. Silverman JG, Decker MR, Reed E, Raj A. Intimate partner violence victimization prior to and during pregnancy among women residing in 26 US states: Associations with maternal and neonatal health. Am J Obstet Gynecol. 2006;195:140-8.

31. Bailey BA. Partner violence during pregnancy: prevalence, effects, screening, and management. Int J Womens Health. 2010;2:183-97.

32. Rodrigues $T$, Rocha $L$, Barros $H$. Physical abuse during pregnancy and preterm delivery. Am J Obstet Gynecol. 2008;198.

33. Coker AL, Sanderson M, Dong B. Partner violence during pregnancy and risk of adverse pregnancy outcomes. Paediatr Perinat Epidemiol. 2004;18:260-9.

34. Mechanic MB, Weaver TL, Resick PA. Mental health consequences of intimate partner abuse: a multidimensional assessment of four different forms of abuse. Violence Against Women. 2008;14:634-54. doi:10.1177/1077801208319283.

35. Dunn LL, Oths KS. Prenatal predictors of intimate partner abuse. J Obstet Gynecol Neonatal Nurs. 2004;33:54-63.

36. Neggers $Y$, Goldenberg R, Cliver $S$, Hauth J. The relationship between psychosocial profile, health practices, and pregnancy outcomes. Acta Obstet Gynecol Scand. 2006;85:277-85.

37. Taft AJ, Small R, Hegarty KL, Watson LF, Gold L, Lumley JA. Mothers' AdvocateS In the Community (MOSAIC)-non-professional mentor support to reduce intimate partner violence and depression in mothers: a cluster randomised trial in primary care. BMC Public Health. 2011;11.

38. Janssen PA, Heaman MI, Urquia ML, O'Campo PJ, Thiessen KR. Risk factors for postpartum depression among abused and nonabused women. Am J Obstet Gynecol. 2012;207:489-8. doi:10.1016/j.ajog.2012.09.022.

39. Janssen PA, Holt VL, Sugg NK, Emanuel I, Critchlow CM, Henderson AD Intimate partner violence and adverse pregnancy outcomes: a populationbased study. Am J Obstet Gynecol. 2003;188:1341-7. S0002937803001042 [pii]. 
40. Sharps PW, Campbell J, Baty ML, Walker KS, Bair-Merritt MH. Current evidence on perinatal home visiting and intimate partner violence. J Obstet Gynecol Neonatal Nurs. 2008;37:480-90. doi:10.1111/j.1552-6909.2008.00267.x.

41. Petersen R, Gazmararian J, Andersen CK. Partner violence: implications for health and community settings. Womens Health Issues. 2001;11:116-25.

42. McFarlane J, Parker B, Soeken K, Bullock L. Assessing for abuse during pregnancy. Severity and frequency of injuries and associated entry into prenatal care. JAMA. 1992;267:3176-8.

43. Macy RJ, Martin SL, Kupper LL, Casanueva C, Guo S. Partner violence among women before, during, and after pregnancy: multiple opportunities for intervention. Womens Health Issues. 2007;17:290-9. doi:10.1016/j.whi.2007.03.006.

44. Certain HE, Mueller M, Jagodzinski T, Fleming M. Domestic abuse during the previous year in a sample of postpartum women. J Obstet Gynecol Neonatal Nurs. 2008;37:35-41. doi:10.1111/j.1552-6909.2007.00200.x.

45. Morland LA, Leskin GA, Block CR, Campbell JC, Friedman MJ. Intimate partner violence and miscarriage: examination of the role of physical and psychological abuse and posttraumatic stress disorder. J Interpers Violence. 2008;23:652-69. doi:10.1177/0886260507313533.

46. Pieters J, Italiano P, Offermans AM, Hellemans S. Ervaringen van vrouwen en mannen met psychologisch, fysiek en seksueel geweld. 2010.

47. Tiwari A, Leung WC, Leung TW, Humphreys J, Parker B, Ho PC. A randomised controlled trial of empowerment training for Chinese abused pregnant women in Hong Kong. BJOG. 2005;112:1249-56.

48. Tiwari A, Chan KL, Fong D, Leung WC, Brownridge DA, Lam H, et al. The impact of psychological abuse by an intimate partner on the mental health of pregnant women. BJOG. 2008;115:377-84. doi:10.1111/j.1471-0528.2007.01593.x.

49. Ludermir AB, Lewis G, Valongueiro SA, de Araujo TVB, Araya R. Violence against women by their intimate partner during pregnancy and postnatal depression: a prospective cohort study. Lancet. 2010;376:903-10.

50. Raffo JE, Meghea Cl, Zhu Q, Roman LA. Psychological and physical abuse among pregnant women in a Medicaid-sponsored prenatal program. Public Health Nurs. 2010;27:385-98. doi:10.1111/j.1525-1446.2010.00871.x.

51. Goldenberg RL, Hickey CA, Cliver SP, Gotlieb S, Woolley TW, Hoffman HJ. Abbreviated scale for the assessment of psychosocial status in pregnancy: Development and evaluation. Acta Obstet Gynecol Scand. 1997;76:19-29.

52. Nast I, Bolten M, Meinlschmidt G, Hellhammer DH. How to measure prenatal stress? A systematic review of psychometric instruments to assess psychosocial stress during pregnancy. Paediatr Perinat Epidemiol. 2013;27:313-22. doi:10.1111/ppe.12051.

53. Copper RL, Goldenberg RL, Das A, Elder N, Swain M, Norman G, et al. The preterm prediction study: maternal stress is associated with spontaneous preterm birth at less than thirty-five weeks' gestation. National Institute of Child Health and Human Development Maternal-Fetal Medicine Units Network. Am J Obstet Gynecol. 1996;175:1286-92.

54. Li Q, Hankin J, Wilsnack SC, Abel EL, Kirby RS, Keith LG, et al. Detection of alcohol use in the second trimester among low-income pregnant women in the prenatal care settings in Jefferson County, Alabama. Alcohol Clin Exp Res. 2012;36:1449-55. doi:10.1111/j.1530-0277.2012.01745.x.

55. Dasari P, Kodenchery MM. Psychological factors in preterm labor and psychotherapeutic intervention. Int J Gynaecol Obstet. 2007;97:196-7. doi:10.1016/j.jijgo.2007.03.006.

56. Sharps PW, Laughon K, Giangrande SK. Intimate partner violence and the childbearing year: maternal and infant health consequences. Trauma Violence Abuse. 2007:8:105-16. doi:10.1177/1524838007302594.

57. Gazmararian JA, Petersen R, Spitz AM, Goodwin MM, Saltzman LE, Marks JS Violence and reproductive health: current knowledge and future research directions. Matern Child Health J. 2000;4:79-84.

58. Ramsay J, Carter Y, Davidson L, Dunne D, Eldridge S, Hegarty K, et al. Advocacy interventions to reduce or eliminate violence and promote the physical and psychosocial well-being of women who experience intimate partner abuse. Cochrane Database Syst Rev. 2009(3);Art.No.:CD005043. doi:10.1002/14651858.CD005043.pub2.

\section{Submit your next manuscript to BioMed Central and take full advantage of:}

- Convenient online submission

- Thorough peer review

- No space constraints or color figure charges

- Immediate publication on acceptance

- Inclusion in PubMed, CAS, Scopus and Google Scholar

- Research which is freely available for redistribution

Submit your manuscript at www.biomedcentral.com/submit 